\title{
Análise dos modelos institucionais de regulação econômica da exploração do petróleo nos EUA, Brasil, Argentina, Venezuela e Arábia Saudita
}

\author{
Analysis of institutional and regulation models of the oil sector in the USA, Brazil, Argentine, Venezuela and Saudi Arabia
}

\author{
Luís Antônio Licks Missel Machado', Divanildo Triches² \\ ' Universidade do Vale do Rio do Sinos \\ ${ }^{2}$ Dr. em Economia pela Universidade Federal do Rio Grande do Sul, Professor pesquisador no PPGE \\ da Universidade do Vale do Rio do Sinos
}

\begin{abstract}
Resumo
O artigo tem o objetivo de investigar as formas institucionais de regulação da produção de petróleo dos Estados Unidos, Brasil, Argentina, Venezuela e Arábia Saudita, especialmente do ponto de vista da forma contratual e do nível de intervenção direta do Estado. A concepção teórica da regulamentação tende a acomodar os interesses de grupos de pressão política, sobretudo as indústrias reguladas e os consumidores, como forma de apoio político ao governo. O petróleo é insumo estratégico no cenário da economia internacional. Os Estados tendem a apoiar as empresas produtoras de petróleo, procurando participar dos ganhos pela sua extração. Assim, buscou-se demonstrar as cinco realidades distintas quanto à produção, ao consumo, à capacidade de refino e ao comércio do petróleo nos países estudados, bem como as formas de arranjos institucionais distintos pelos quais esses países regulam a exploração do petróleo, seja através de contratos de concessão e institucionalização de agências reguladoras do setor, como os Estados Unidos, seja apenas com contratos de concessão sem agências reguladoras, como na Argentina. No caso venezuelano, existe apenas contrato de joint-venture entre a iniciativa privada e a empresa estatal. Na Arábia Saudita, há um monopólio absoluto no setor de propriedade estatal. No Brasil, verifica-se a existência de contratos de concessão, agência reguladora e uma única empresa de capital estatal.
\end{abstract}

Palavras Chave: Produção de petróleo, regulamentação institucional, concessão.

\begin{abstract}
This paper aims to investigate the institutional and the regulation models of the production of oil of the United States, Brazil, Argentina, Venezuela and Saudi Arabia, especially contractual point of view and the level of government intervention. The theoretical conception of the regulation tends to accommodate the interests of lobbies politics, mainly the regulated industries and the consumers, as form of political support to the government. The oil is a strategical factor in the international economy. Govornments tend to support the producing companies of oil and they look for to participate in the profits for its extraction. Thus, it was demonstrated the five distinct realities how much to the production, consumption, capacity of refining and trade of the oil in the studied countries. It was also studied the forms of distinct institutional arrangements for which these countries regulate the exploration, either through contracts of concession and institutionalization of regulating agencies of the sector, as the United States, or only with contracts of concession as in Argentina. In the Venezuelan case, there is only a contract of joint-venture between the private initiative and the state-owned company. Saudi Arabia has an absolute monopoly in the oil sector of state property. In Brazil, there are a concession contract, regulating agency and one company of state capital
\end{abstract}

Keywords: Production of petroleum, institutional and regulation, concession.

JEL Classification: H62, H63, E63 


\section{INTRODUÇÃO}

Em geral, os países apresentam características sociais e institucionais peculiares, e que se traduzem em políticas econômicas distintas, inclusive no que diz respeito à forma de atuação e regulação do setor de exploração do petróleo. Sob essa análise, a regulação do setor pode ser vista como elemento favorável ao aumento da produção de petróleo no mundo, atraindo novos contratantes ou mesmo criando condições de maior segurança jurídica para a exploração petrolífera. Nesse contexto, o petróleo passa a ser, talvez, um dos principais exemplos e motivador das análises de interesse da economia internacional que, conforme abordam Krugman e Obstfeld (2007), consiste em questões levantadas pelos problemas especiais da interação econômica entre Estados soberanos.

As principais linhas teóricas reconhecidas pela teoria econômica da regulação foram originadas nas concepções de Stigler (1971), Peltzman (1976), Becker (1983) e Laffont e Tirole (1993). Os modelos foram passíveis de controvérsias em vista de que a economia, como um fenômeno social, está evidentemente sujeita às transformações evolutivas da sociedade através dos tempos, e justamente por essa característica é que os modelos econômicos foram incorporarando as modificações clamadas pela sociedade. Nesse contexto, adiantando-se à conclusão de Fiani (2004), o principal aspecto da análise evolutiva efetuada é que os modelos econômicos seminais ainda não se encontram completos em seus elementos e variáveis, devendo ser acrescentados os aspectos institucionais de cada país, quando se busca a aplicação dessa teoria ao mercado.

A partir dessa constatação, buscou-se a importância do aspecto institucional para aperfeiçoamento da teoria econômica da regulação, pelo entendimento de North (1990) a respeito da denominada teoria institucional da regulação econômica, em que, segundo o autor, a conformação institucional de um país seria mais importante até mesmo do que a tecnologia para a obtenção de eficiência econômica.

Nesse sentido, este artigo tem o objetivo de investigar as formas institucionais de regulação da produção de petróleo nos Estados Unidos, Brasil, Argentina, Venezuela e Arábia Saudita, especialmente do ponto de vista da forma contratual e como esses países concedem a exploração em seus territórios, bem como do nível de intervenção direta do Estado. Além disso, discute-se o nível das reservas, a produção, o consumo e a capacidade das refinarias nacionais, bem como um indicativo da situação da balança comercial. As informações estatísticas deixam claras as situações distintas de cada uma das economias em relação a esse setor estratégico da economia mundial. Para tanto, além dessa introdução, a estrutura do artigo apresenta, na seção 2, uma breve revisão das principais teorias econômicas de regulação. A análise comparativa da indústria petrolífera é desenvolvida na seção 3 . Os aspectos institucionais reguladores dos países selecionados encontram-se abordados na seção 4 . Por fim, a seção 5 apresenta as conclusões.

\section{REVISÃO DAS PRINCIPAIS TEORIAS ECONÔMICAS DE REGULAÇÃOO}

A regulação dos mercados tinha como principal objetivo, segundo Stigler (1971), a proteção dos interesses de grupos de indústrias, podendo o Estado conceder: (a) subsídios monetários; (b) controle sobre a entrada de novos entrantes (que pode assumir a forma de uma proteção tarifária); (c) intervenção nos mercados de produtos substitutos ou complementares e controle de preços (visando à obtenção de taxas de retorno acima dos níveis competitivos). $\mathrm{O}$ mercado, como instrumento de decisão econômica, era substituído por um processo político de decisão e, portanto, a intervenção do Estado na atividade econômica se fazia necessária por causa da ineficiência econômica ou falhas de mercado. Para Stingler (1971), na maior parte das vezes, as firmas capturam o Estado, o que é caracterizado quando as exigências regulamentares passam a se amoldar às conveniências das unidades reguladas, e beneficiam-se da proteção do órgão regulador.

As dificuldades encontradas no âmbito das concepções teóricas de Stigler (1971) são tratadas por Peltzman (1976), que procura solucioná-las via abordagem da função de apoio do regulador, em relação à função lucro da empresa. Para o autor, a regulação não visa fundamentalmente a proteger a indústria regulada, mas o resultado consequente da ação de grupos de interesses, especialmente produtores e consumidores, cujas pressões políticas têm sentido antagônico. Já Becker (1983) tratou o elemento eficiência a ser considerado em termos de ganhos líquidos agregados. Por esse modelo, deve ser considerado em sua forma mais simples o confronto de dois grupos de interesse, $S$ e $T$, sendo que a renda é transferida, via regulação, dos membros de um grupo para os membros de outro. Assim, sendo Rt a renda retirada de cada membro do grupo de interesse $T$ para os membros de $S$, e $n T$ o número de membros do grupo $T$, logo 
tem-se que:

$$
S=n T x F(R t))
$$

Assim, pela análise do modelo de Becker (1983), conforme a equação (1), o sucesso de um grupo de interesse, seja de produtores seja de consumidores, pela competição e pelo posicionamento de apoio político mediante a regulação econômica, depende de seus ganhos líquidos em função das perdas do outro grupo de interesse. Assim, como resultado disso, tinha-se que o Estado regulador, na maior parte dos casos, intervinha na economia buscando aumentar a eficiência do sistema, ainda que em decorrência da ação de grupos de interesse em detrimento de outros.

A teoria de regulação econômica passou a ser visualizada por outro viés, mais complexo, a partir de Laffont e Tirole (1993), que passaram a abordar a questão das escolhas de regulamentação por parte do Estado em termos de eficiência dessa regulação. Para isso, abordam a questão de incentivos para corrigir o problema de assimetria de informações existentes no processo de regulação econômica, até então conhecida. O modelo desenvolvido pelos autores teve como ponto de partida a especificação da função custo, C, da indústria regulada, como expressa a equação (2):

$$
C=(\beta-e) q
$$

Em que o parâmetro $\beta$ pode assumir os valores $\beta 1$ ou $\beta 2 \operatorname{com} \beta 2>\beta 1$, e probabilidades $v$ para $\beta 1$ e (1-v) para $\beta 2$, representando $\beta 2$ a tecnologia da firma menos eficiente e $\beta 1$ a tecnologia da firma mais eficiente, enquanto $e$ representa o esforço administrativo redutor de custos. Destaca-se que o nível de esforço $(e)$ despendido pela indústria regulada é um fator essencial na determinação dos custos totais: quanto maior $e$, menores os custos. Contudo, o esforço dos executivos para reduzir os custos não é neutro no modelo: os executivos da firma regulada apresentam uma função de desutilidade crescente e convexa, representada por $\Psi(e)$, em que as condições de primeira e de segunda ordem são positivas.

Para validação do modelo proposto por Laffont e Tirole (1993), convenciona-se que o Estado atua reembolsando os custos com uma transferência líquida à indústria, e apropria-se da receita das vendas dos produtos, como argumenta Fiani (2004). A partir dessa nova concepção, passa-se a identificar a existência de três sujeitos principais no contexto regulatório, quais sejam: as indústrias (e seu contraponto representado pelos consumidores), o Estado, e o órgão regulador ou agência. Nesse sentido, o problema surge quando há a assimetria de informação entre o Estado (governo) e a agência reguladora. Assim, nota-se muito claramente a importância da simetria das informações, seja em relação às indústrias reguladas e as agências reguladoras, seja entre estas e o Estado. Desse modo, o aparato regulatório é criado com a finalidade de resolver as imperfeições do mercado. Assim, Triches (1998), Nunes et al.(2007) mostram que dentre as formas usuais de regulação, destacam-se:

i) preços máximos: o sistema de regulação de bens e serviços coletivos pelo preço máximo leva em consideração dois aspectos básicos: o controle geral do nível de preços e o controle da estrutura de preços relativos ${ }^{1} \mathrm{O}$ cálculo utilizado, para tanto, baseia-se na equação (3):

$$
P=R P I-X
$$

Em que P é a tarifa, ou preço a ser estabelecido, RPI é o índice geral de preços e X é um fator que capta os efeitos de aumento da produtividade do setor em particular. Em outras palavras, o órgão regulador fixa o preço de todos os bens e serviços a um limite superior, e abaixo dele a firma tem plena liberdade para praticar seu preço;

ii) taxa de retorno: a regulação econômica baseada na taxa de retorno é amplamente utilizada nos Estados Unidos. É uma metodologia que envolve uma comissão de gerenciamento das atividades relativas ao fornecimento de serviços de utilidade pública ou agência reguladora. A comissão tem o papel de estabelecer uma taxa conveniente de retorno sobre o investimento na indústria regulada. Essa sistemática de regulação evita que se obtenham lucros monopolísticos. Os reguladores permitem que a firma regulada tente atingir a maximização dos lucros, exatamente como se a regulação não existisse, exceto na fixação dos preços. Assim sendo, a firma maximiza o lucro total, e está sujeita a uma restrição regulada, conforme as equações (4) a (5):

$$
\pi=P q-w l-r k
$$

sujeito a

$$
P q-w l \leq z
$$

onde $z=r+v$ em que $\pi$ é lucro total; $\mathrm{P}$, preço do

\footnotetext{
1 Para uma abordagem sobre a regulação por preço máximo, que
} leve em consideração incentivos e informação, veja-se Sibley (1989). 
produto; q, quantidade produzida; L, quantidade de mão de obra empregada, w, taxa de salário; $\mathrm{K}$, quantidade do capital usado; r, custo da unidade de capital; z, a taxa de retorno permitida pela regulamentação e v é um fator de decisão política maior ou igual a zero. Permite-se que a firma regulada tenha uma taxa de retorno pelo menos igual ao valor implícito do estoque de capital $\mathrm{r}$. A taxa de retorno pode ser maior do que $r$, e depende de v. Portanto, essa metodologia depende do levantamento de informações pertinentes aos custos de operação das empresas, de capital empregado, taxa interna de retorno, maturação dos investimentos, etc. A partir dessas informações amplamente analisadas e avaliadas, o órgão regulador determina qual deve ser o valor de v e, por consequência, o valor de $\mathrm{z}$;

iii) concorrência referencial: o sistema de regulação econômica ou estabelecimento de preços, por meio da concorrência referencial, ocorre quando não existe possibilidade concreta de reforçar a concorrência de mercado diretamente, ou por meio de produtos similares. ${ }^{2}$ Esse procedimento, normalmente, é usado devido à existência de um elevado grau de assimetria de informação entre o órgão regulador e as firmas reguladas, o que implica a redução da eficiência da regulação.

Ao concluir sua análise sobre os contextos representados por essas teorias, que evoluíram mediante observação científica do fenômeno econômico, Fiani (2004) argumenta que, ao tratar o fenômeno institucional de forma pouco aprofundada, esses modelos acabam por se tornar de utilidade muito limitada para os casos concretos de regulação. Sob essa abordagem, Marques-Pereira

$2 \mathrm{Na}$ literatura, esse tipo de regulamentação é conhecido como Yardstick Competition. Para maiores detalhes, vejam-se Laffont e Tirole (1993, p. $84-86)$.
(1998) salienta que a teoria da regulação destacou-se no pensamento econômico-institucionalista, como um dispositivo conceitual mais particularmente adequado pela formalização que produziu do quadro de compromissos institucionalizados.

\section{ANÁLISE COMPARATIVA DA INDÚSTRIA PETROLÍFERA}

As reservas mundias de petróleo comprovadas atingiram, no final de 2009, o volume estimado de 1,333 trilhões de barris como mostra a tabela 1. O Oriente Médio responde por 754,2 bilhões de barris, ou seja, $56,57 \%$ das reservas globais, e a Arábia Saudita é o país de maior reserva mundial, responsável por 264,6 bilhões de barris de petróleo ou quase um quinto do total mundial. A Venezuela e os Estados Unidos aparecem no ano de 2009 , com $12,92 \%$ e $2,13 \%$, respectivamente. Os demais países, em termos de reservas globais, representam quase $64 \%$ que correspondem, em valores absolutos, a 852,4 bilhões de barris.

Em vinte anos, as reservas mundiais de petróleo, ainda de acordo com a tabela 1, aumentaram $32,46 \%$. Nesse período, a participação de EUA, Brasil, Argentina e Venezuela passou a representar $16,21 \%$ das reservas totais, sendo que, em 1999, essa proporção era de 10,85\% e, em 1989, apenas 9,77\%. A Arábia Saudita, por sua vez, vem reduzindo sua representatividade em termos globais, embora suas reservas tenham aumentado 1,73\% no período entre 1989 e 2009 . Já os EUA apresentaram uma diminuição de 1,30 bilhões de barris de petróleo, o que representa uma queda de 4,38\%. A Argentina também apresentou diminuição de suas reservas durante tal período, em 0,60 bilhões de barris, o que representa 19,35\%.

Tabela 1 - Evolução das reservas mundiais de petróleo no período de 1989 a 2009

\begin{tabular}{l|r|r|r|r|r|r}
\hline País/Ano & \multicolumn{1}{|c|}{1989} & \multicolumn{1}{c|}{$\%$} & \multicolumn{1}{c|}{1999} & \multicolumn{1}{c|}{$\%$} & \multicolumn{1}{c}{2009} & \multicolumn{1}{c}{$\%$} \\
\hline EUA & 34,3 & 3,41 & 29,7 & 2,74 & 28,4 & 2,13 \\
\hline Brasil & 2,8 & 0,28 & 8,12 & 0,75 & 12,9 & 0,97 \\
\hline Argentina & 2,2 & 0,22 & 3,1 & 0,29 & 2,5 & 0,19 \\
\hline Venezuela & 59,0 & 5,86 & 76,8 & 7,07 & 172,3 & 12,92 \\
\hline Arábia Saudita & 260,1 & 25,84 & 262,8 & 24,21 & 264,6 & 19,85 \\
\hline Demais países & 648,0 & 64,39 & 705,0 & 64,94 & 852,40 & 63,94 \\
\hline Total mundial & 1006,4 & 100 & 1085,6 & 100 & 1333,1 & 100 \\
\hline
\end{tabular}

Fonte: Statistical Review of World Energy (2010).

Nota: Dados em bilhões de barris. 
O Brasil e a Venezuela apresentaram um aumento significativo de suas reservas comprovadas entre 1999 e 2009 . O primeiro apresentou um aumento das reservas em 4,78 bilhões de barris, o que representa um aumento de $58,87 \%$, enquanto, na Venezuela, o aumento de reservas foi de 95,50 bilhões de barris, uma variação positiva de $80,42 \%$. Salienta-se que, durante o ano de 2010, a Agência Nacional de Petróleo (ANP) projeta um potencial de reservas da chamada camada pré-sal em um volume de cinquenta a cem bilhões de barris, levando o País a ocupar a 16 . $^{\mathrm{a}}$ posição no ranking mundial de maiores reservas (OPEP, 2010).

No que tange à produção mundial de petróleo (upstream), em 2009 ela foi de 79.948 mil barris por dia, o que representa uma produção $10,54 \%$ maior do que a registrada em 1999, como revela a tabela 2. Nesse ano, a soma da produção de petróleo de Brasil, Argentina e Venezuela, era igual a $66,05 \%$ da produção de petróleo dos Estados Unidos. Em 2004, esse somatório foi igual a $71,98 \%$ e, em 2009 , a produção conjunta desses países foi $71,46 \%$ da produção norte-americana. A participação na produção de petróleo, desses três países latinos-americanos, manteve-se em torno de $43 \%$ do total do continente, no período de 1999 a 2009.

A produção brasileira de petróleo representou $30,01 \%$ da produção continental em 2009, com um crescimento anual médio de $6 \%$, contrastando com o aumento de produção continental americano, em média 0,09\% ao ano ao longo de 1999 a 2009. A Argentina vem diminuindo a sua produção de petróleo, registrando um crescimento médio anual negativo de 0,98\%. Em 2009, esse país exibiu uma participação $10 \%$ da produção continental e apenas $0,85 \%$ da produção mundial. Já a produção da Venezuela foi, em 1999, de 4,32\% do total mundial, enquanto dez anos após essa proporção caiu para 3,05\%. A diminuição da produção da Venezuela fica mais evidente, quando se compara sua produção interna com os resultados da produção continental. Em 1999, a produção venezuelana representava $26,48 \%$ da produção latino-americana e caiu para 20,48\% em 2009.

Comparando-se a produção de petróleo dos Estados Unidos, maior consumidor importador mundial, com a Arábia Saudita, o maior produtor e exportador de petróleo do mundo, nota-se ainda, na tabela 2 , que o primeiro tem reduzido a diferença de produção em relação ao segundo nos anos de 1999 a 2009. Os Estados Unidos produziram, em 2004, mais ou menos dois terços daquilo que foi produzido pela Arábia Saudita, enquanto que, em 2009, essa relação aumentou para 74,09\%.

A capacidade de refino de petróleo (midstream) da economia mundial, em 2009, foi equivalente a 90.662 mil barris por dia, como retrata a tabela 3, comparativamente ao ano de 1999, quando a capacidade de refino mundial era de 82.452 mil barris diários. Isso significa que a capacidade global de refino do mundo aumentou em aproximadamente $10 \%$. A capacidade de refino é um indicativo de aproveitamento da produção de petróleo de cada país, bem como de capacidade de suprimento do consumo interno.

Os Estados Unidos tiveram a capacidade de refino de petróleo aumentada em média de 0,69\% ao ano ao longo dos anos de 1999 até 2009. Apesar disso, a participação norte-americana sobre o potencial total de refino do mundo caiu $0,52 \%$ no mesmo período. Em 2009, a produção de petróleo daquela economia supriu apenas $40,68 \%$ da capacidade de suas refinarias e $38,51 \%$ do consumo interno. Ainda que as refinarias tenham capacidade muito acima da produção local, conseguiram suprir

Tabela 2 - Evolução da produção mundial de petróleo comparada no período de 1999 a 2009

\begin{tabular}{l|r|r|r|r|r|r}
\hline País/Ano & \multicolumn{1}{|c|}{1999} & \multicolumn{1}{c|}{$\%$} & \multicolumn{1}{c|}{2004} & \multicolumn{1}{c|}{$\%$} & \multicolumn{1}{c}{2009} & \multicolumn{1}{c}{$\%$} \\
\hline EUA & 7.731 & 10,69 & 7.228 & 9,01 & 7.196 & 9,00 \\
\hline Brasil & 1.133 & 1,57 & 1.542 & 1,92 & 2.029 & 2,54 \\
\hline Argentina & 847 & 1,17 & 754 & 0,94 & 676 & 0,85 \\
\hline Venezuela & 3.126 & 4,32 & 2.907 & 3,62 & 2.437 & 3,05 \\
\hline Demais América Latina & 6.699 & 9,27 & 6.680 & 8,32 & 6.760 & 8,46 \\
\hline Arábia Saudita & 8.853 & 12,24 & 10.638 & 13,25 & 9.713 & 12,15 \\
\hline Demais do mundo & 43.936 & 60,75 & 50.507 & 62,93 & 51.137 & 63,96 \\
\hline Total mundial & 72.325 & 100,00 & 80.256 & 100,00 & 79.948 & 100,00 \\
\hline
\end{tabular}

Fonte: Statistical Review of World Energy (2010).

Nota: Dados em milhares de barris diários. 
Tabela 3 - Capacidade mundial de refino de petróleo comparada no período de 1999 a 2009

\begin{tabular}{l|r|r|r|r|r|r}
\hline País/Ano & \multicolumn{1}{|c|}{1999} & \multicolumn{1}{c|}{$\%$} & \multicolumn{1}{c|}{2004} & \multicolumn{1}{c|}{$\%$} & \multicolumn{1}{c}{2009} & \multicolumn{1}{c}{$\%$} \\
\hline EUA & 16.512 & 20,03 & 17.125 & 20,14 & 17.688 & 19,51 \\
\hline Brasil & 1.796 & 2,18 & 1.915 & 2,25 & 2.066 & 2,28 \\
\hline Argentina & 643 & 0,78 & 623 & 0,73 & 635 & 0,70 \\
\hline Venezuela & 1.248 & 1,51 & 1.306 & 1,54 & 1.311 & 1,45 \\
\hline Demais América Latina & 6.210 & 7,53 & 6.393 & 7,52 & 6.687 & 7,38 \\
\hline Arábia Saudita & 1.823 & 2,21 & 2.075 & 2,44 & 2.100 & 2,32 \\
\hline Demais mundial & 54.220 & 65,76 & 55.612 & 65,39 & 60.175 & 66,37 \\
\hline Total mundial & 82.452 & 100,00 & 85.049 & 100,00 & 90.662 & 100,00 \\
\hline
\end{tabular}

Fonte: Statistical Review of World Energy (2010).

Nota: Dados em milhares de barris diários.

apenas $94,66 \%$ da demanda do mercado interno. Pode-se afirmar, portanto, que a economia norte-americana é altamente dependente de petróleo externo. No ano de 2009, os EUA importaram 9.062,3mil barris/dia de petróleo, contrastando com suas exportações de apenas 43,07mil barris/ dia segundo a Opep (2010).

Salienta-se que o Brasil, a Argentina e a Venezuela juntos participaram com $60,0 \%$ da capacidade de refino do petróleo da América Latina em 2009. O Brasil é o país do continente com maior capacidade de refino, e o único que apresentou aumento da representatividade em termos de total mundial da capacidade de suas refinarias. $\mathrm{O}$ crescimento médio da capacidade de refino do Brasil de 1999 a 2009 foi de 1,41\% ao ano. A Argentina, também nesse período, teve sua capacidade de refino reduzida em uma média anual de $-0,13 \%$, enquanto a Venezuela apresentou um incremento médio, na capacidade de suas refinarias, de $0,49 \%$ ao ano.

O Brasil e os Estados Unidos apresentam capacidade de refino do petróleo menor do que as suas respectivas demandas internas, porém em proporções diferentes. A produção brasileira, em 2009 , foi equivalente a $98,21 \%$ da capacidade de suas refinarias e $84,37 \%$ do consumo interno. A capacidade das refinarias do Brasil correspondeu a $85,90 \%$ do consumo de petróleo da economia nacional. A economia brasileira ainda é dependente do petróleo externo, como um importador líquido de petróleo, tendo importado, em 2009, $360,1 \mathrm{mil}$ barris/dia, conforme a Opep (2010), embora o país tenha exportado 154,8 mil barris/ dia nesse ano. Isso poderá se alterar, à medida que se comprovem as expectativas sobre a camada pré-sal. Ainda assim, com aumento da produção local, deverá haver um défice em relação à atual capacidade de refino, uma vez que, segundo os dados de 2009, as refinarias possuem capacidade de refino para um aumento de somente mais 1,82\% na produção de petróleo.

A economia argentina, por sua vez, apresentou uma demanda doméstica de petróleo menor que a produção e a capacidade das refinarias. A demanda interna de petróleo daquele país foi equivalente a $74,49 \%$ da capacidade das refinarias nacionais e $69,97 \%$ da produção interna. Em síntese, a economia argentina é autossuficiente em petróleo, além de ser exportadora líquida de óleo combustível, encerrando o ano de 2009 com uma média estimada de 249 mil barris/dia vendidos ao Exterior, contra 107 mil barris/dia importados de acordo com a Opep (2010).

A economia venezuelana não só mostrou auto-suficiência no setor petrolífero como também um elevado excedente produtivo, o que the confere uma relevância no comércio internacional como um exportador líquido de petróleo, inclusive como integrante da Opep. Em 2009, aquele país vendeu ao mercado externo 1,608 milhões de barris/dia, como aponta a Opep (2010). As refinarias venezuelanas possuíam a capacidade de refinar apenas $53,80 \%$ da produção nacional em 2009 , contra uma demanda de $46,45 \%$ do potencial de refino. Já o país maior produtor mundial de petróleo, a Arábia Saudita, tem a capacidade de processar, domesticamente, apenas $21,62 \%$.

No que concerne ao consumo mundial de petróleo, observa-se, por meio da tabela 4 , que foi de 84,077 milhões barris diários em 2009, o que representou um crescimento de $11,14 \% \mathrm{em}$ relação a 1999. O consumo conjunto do Brasil, da Argentina e da Venezuela, ficou em apenas 18,66\% do consumo de petróleo dos Estados Unidos em 2009. Os Estados Unidos é o maior consumidor de petróleo do mundo, participando com $22,22 \%$ do total mundial. 
Tabela 4 - Consumo mundial de petróleo comparado no período de 1999 a 2009

\begin{tabular}{l|r|r|r|r|r|r}
\hline País/Ano & \multicolumn{1}{|c|}{1999} & \multicolumn{1}{c|}{$\%$} & \multicolumn{1}{c|}{2004} & \multicolumn{1}{c|}{$\%$} & \multicolumn{1}{c}{2009} & \multicolumn{1}{c}{$\%$} \\
\hline EUA & 19.519 & 25,80 & 20.732 & 25,20 & 18.686 & 22,22 \\
\hline Brasil & 2.114 & 2,79 & 1.999 & 2,43 & 2.405 & 2,86 \\
\hline Argentina & 445 & 0,59 & 388 & 0,47 & 473 & 0,56 \\
\hline Venezuela & 474 & 0,63 & 523 & 0,64 & 609 & 0,72 \\
\hline Demais América Latina & 4.905 & 6,48 & 4.871 & 5,92 & 5.653 & 6,72 \\
\hline Arábia Saudita & 1.543 & 2,04 & 1.880 & 2,29 & 2.614 & 3,11 \\
\hline Demais mundial & 46.648 & 61,66 & 51.868 & 63,05 & 53.997 & 64,22 \\
\hline Total mundial & 75.648 & 100,00 & 82.261 & 100,00 & 84.077 & 100,00 \\
\hline
\end{tabular}

Fonte: Statistical Review of World Energy (2010).

Nota: Dados em milhares de barris diários

No período que se estende de 2004 a 2009, a taxa média anual de crescimento do consumo da economia brasileira foi de $3,77 \%$. No final de 2009, o consumo do Brasil representou mais de um quarto de todo o consumo latino-americano. A Argentina e a Venezuela registraram uma elevação média anual, no seu respectivo consumo de petróleo, de 4,04\% e 3,09\%, respectivamente, entre os anos 2004 a 2009. Já o país árabe teve o consumo de petróleo superior ao da economia brasileira apenas em 2009.

Em síntese, o contexto da indústria petrolífera dos países selecionados é bastante distinto no que se refere à produção, ao refino e consumo de petróleo. Pode-se, portanto, agrupar os países em duas categorias: (a) aqueles que apresentam consumo maior do que a capacidade de produção, dentre eles encontram-se os Estados Unidos e o Brasil; (b) aqueles cuja produção é excedente ao consumo, como Argentina, Venezuela e Arábia Saudita.

\section{ASPECTOS INSTITUCIONAIS REGULA- DORES DOS PAÍSES SELECIONADOS}

No contexto institucional, abordam-se os regimes jurídico-regulatórios, cuja diferença entre eles, segundo Bain e Tozzini (2009), é o instrumento político e jurídico a ser estabelecido entre o Estado e a empresa produtora. Dessa forma, a regulação americana é baseada num sistema federativo de pouca, ou sem intervenção federal nos Estados, ou seja, as áreas; (i) onshore de propriedade do governo federal são governadas pelo Ato de Lease Mineral; (ii) offshore localizadas dentro de limites especificados da costa, e as áreas onshore de propriedade de cada governo estadual estão sujeitas à regulação estadual; (iii) onshore de propriedade de tribos indígenas estão sujeitas ao Ato de Desenvolvimento dos Minerais Indígenas; (iv) offshore localizadas na Plataforma Continental em Alto-Mar (Outer Continental Shelf), além dos limites de propriedade estadual, são governadas pelo Ato de Terras da Plataforma Continental Exterior.

A indústria petrolífera norte-americana adota o modelo contratual de concessão e considera a particularidade de cada campo a ser produzido. O contrato permite que sejam inseridas cláusulas específicas ou obrigações especiais a depender do campo de extração do petróleo. As participações governamentais nessa extração, conforme Bain e Tozzini (2009), são: a) bônus, aluguéis e royalties variáveis; b) Imposto de Renda Federal de 35\%; c) tributo sobre a produção entre $2,3 \%$ a $4,6 \%$; ) tributo regulatório de US $\$ 0,001875$ por barril; e) taxa regulatória de US $\$ 0,00625$ por barril; f) tributos estaduais variáveis; g) imposto sobre vendas e sobre uso de $8,25 \%$. A legislação americana permite ao governo repassar parte dos pagamentos dos royalties às refinarias de pequeno porte, a fim de promover o crescimento do setor e possibilitar o ingresso de outros produtores.

As funções desempenhadas pelo Estado brasileiro na economia até 1995, conforme Brito (2004), davam-se por sua conta e risco, sendo vedada por disposição constitucional a inserção de novos atores econômicos. Constituindo-se monopólio do petróleo, por meio da Petrobrás, que assumia o modelo estatal no segmento, como uma política estratégica de desenvolvimento. ${ }^{3}$ Para Valois (2000), essas medidas de ausência de um mercado competitivo implicaram a baixa qualidade dos serviços prestados aos consumidores e a falta

3 A criação do monopólio estatal do petróleo, no Brasil, deu-se por meio da Lei 2.004, de 1953. 
de recursos para a modernização dos serviços. ${ }^{4}$

A partir da Emenda Constitucional 09/1995, alterou-se a função exercida pelo Estado brasileiro nas atividades petrolíferas, com forte viés de privatização, visando, segundo Suslick (2001), a aumentar a eficiência e a ampliação de suas atividades, além de dar ênfase à proteção dos consumidores e usuários quanto ao preço, à qualidade dos produtos e à garantia do suprimento de petróleo em todo o território nacional. Essa Emenda também previu a criação de um órgão regulador para o setor, a Agência Nacional do Petróleo (ANP), atual Agência Nacional do Petróleo, Gás Natural e Biocombustíveis (ANP). ${ }^{5}$

Embora o monopólio natural do setor petrolífero brasileiro tenha sido extinto legalmente, ele de fato continua existindo. Segundo Brito (2004), a Petrobras é ainda detentora da quase totalidade da infraestrutura necessária às atividades da indústria do petróleo. No entanto, o Brasil está passando por modificações substantivas em sua estrutura institucional para a exploração do petróleo, em vista das extrações da camada pré-sal. Para isso foi criada, em agosto de 2010, uma empresa estatal, ou seja, Empresa Brasileira de Administração de Petróleo e Gás Natural S.A. - Pré-Sal Petróleo S.A. (PP-SA) responsável pela administração dos contratos de exploração na camada pré-sal.

Com base na Emenda Constitucional de 1995 e na Lei 9.478/97, também se alterou o mecanismo de transferência de renda da exploração e produção do petróleo, para ampliar a participação governamental pelos contratos de concessão. Até a edição da Lei 9.478/97, a renda transferida ao Estado era a título de royalties e em percentual de 5\% fixo. Após a alteração legal de 1997, a participação governamental passou a ser: (a) royalties, $5 \%$ a 10\%; (b) bônus de assinatura; (c) participação especial com alíquotas progressivas de $10 \%, 20 \%, 30 \%, 35 \%$ e $40 \%$; (d) pagamento pela ocupação/retenção da área. Somando-se a isso, ainda se instituiu a participação de proprietário da terra $-0,5 \%$ a $1 \%$ do valor de produção de petróleo e gás em terra.

4 Outros estudos sobre o setor de petróleo no Brasil são de Marques-Pereira (1998), Matos et al (2005), Mello (2001), Pires e Campo Filho (2004), Queiroz e Postali ( 2010), Suslick (2001), entre outros. 5 Foi instituída pela Lei 9.478/97, com a função de regular o monopólio da União, pelo que, ao contrário do modelo estatal anteriormente utilizado não há atuação diretamente no domínio econômico, promovendo e capitalizando esse setor. ANP tem o objetivo de promover: a) a proteção dos interesses dos consumidores quanto ao preço, à qualidade e oferta dos produtos; (b) a garantia do suprimento de derivados de petróleo em todo o território nacional; (c) administração, em nome da União, do monopólio de pesquisa e lavra do petróleo. (BRASIL, 1997).
Salienta-se que essa alteração institucional reforça a ideia de que o governo brasileiro optou pelo apoio político da indústria de produção, tendo a preocupação regulatória que possibilitasse o incremento de suas receitas. Para Queiroz e Postali (2010), o pagamento de royalties aos Estados e Municípios é justificado tanto como uma compensação financeira pelos impactos e pela externalidades negativas que a atividade petrolífera causa às localidades em que ocorrem suas atividades produtivas, quanto como uma forma de garantir o bem-estar integral em áreas dependentes de recursos finitos. Os critérios estabelecidos para os estados beneficiários estão baseados nos municípios que integram o espaço geográfico da produção de petróleo, ou seja: (a) o município deve ser considerado um "produtor"; ou (b) o município deve ser direta ou indiretamente afetado pela produção de petróleo e/ou gás, como discute Serra (2003).

Por outro lado, Campos (2004, 2005) demonstra que a desestabilidade política vivenciada pela economia argentina provocou constantes mudanças no setor petrolífero, como foi o caso da alteração promovida pelo governo constitucional de 1973 a 1976, que retornou às condições anteriores a 1967, favoráveis à empresa que detinha o monopólio do setor, Yacimientos Petroliferos Fiscales de Argentina (YPF). ${ }^{6}$ Porém, após novo golpe de Estado, alterou-se novamente a política estratégica argentina, transferindo-se as áreas de produção para a iniciativa privada, incluindo instalações em pleno funcionamento, e a promulgação dos contratos de risco.

O processo de desregulação e de privatização do setor petrolífero iniciou-se em outubro de 1989, pelo Decreto 1.055/89, com a privatização das jazidas de hidrocarbonetos, regulamentando-se uma nova forma de concessão mediante o pagamento de um direito de exploração. $\mathrm{O}$ governo argentino autorizou um plano para que as empresas privadas associassem-se à YPF. No caso de descoberta de novas jazidas de petróleo, as empresas detentoras poderiam exportar ou vender internamente o petróleo. Em outubro de 1992, foram transferidas as propriedades das jazidas petrolíferas aos Estados, e estabeleceu-se a privatização da YPF com a venda de suas ações. Pelo sistema normativo argentino, com base no Decreto 450/94, as empresas interessadas em uma área de exploração

\footnotetext{
6 Após a destituição de Arturo Frondizi do cargo de Presidente da República, em 1961, o Congresso Nacional aprovou a Lei 14.773/61, que outorgava o monopólio ao Estado e proibia concessões. Porém, com o golpe Militar de 1967, alterou-se novamente a política do petróleo pela Lei 17.319/67, que permitiu a produção intensiva das jazidas de petróleo já descobertas em território argentino.
} 
e de produção precisam cadastrar-se no Registro de Companhias Petrolíferas da Secretaria de Energia da Argentina. Os contratos de operação conjunta, entre o operador e os concessionários e permissionários de exploração e produção de petróleo na Argentina, outorgam o direito exclusivo de explorar as reservas petrolíferas da área outorgada.

O contrato de concessão surge a partir da permissão de exploração, em que se descubram hidrocarbonetos ou mediante licitação de áreas já provadas, conferindo ao seu titular o direito de extrair os hidrocarbonetos e obter o seu domínio. Enquanto durar o contrato, os concessionários ou permissionários pagarão ao governo, segundo Bain e Tozzini (2009), a remuneração de: a) royalties de $12 \%$ a $5 \%$, de acordo com a produtividade, as condições e a localização dos poços, sobre o valor bruto da produção; b) imposto especial, variável em percentual sobre a apuração líquida que obtenham no exercício da atividade de permissionários ou concessionários; c) taxas, de US\$ 86,71 por quilômetro quadrado no primeiro ano, US $\$ 173,37$ no segundo, e US\$ 260,4 no terceiro. Já, na prorrogação, o mínimo é de US\$ 17.342,65 por quilômetro quadrado.

No caso da Venezuela, segundo Barros (2006), a empresa exploradora de petróleo, a Petróleo de Venezuela S.A. (PDVSA), sempre teve grande autonomia em relação ao governo. Essa política liberou a entrada de capitais transnacionais nas atividades primárias. Entretanto, sob o governo Chávez, o Estado assumiu o controle da principal companhia do país que foi fundamento para uma mudança de rumo, em que se destaca o período de inflexão, marcado por uma crise econômica com poucos precedentes fora de Estado de Guerra conforme aborda Barros (2006). ${ }^{7}$

Isento da nova regulação, o governo venezuelano converteu os termos dos acordos anteriores à nova regulação em joint ventures, denominadas empresas mixtas. As operações de petróleo na Venezuela estão sob controle da (PDVSA), seja diretamente realizado pela empresa estatal, seja pelo controle acionário das empresas mixtas, responsáveis pelas operações, conforme determina a Lei Orgânica de Hidrocarbonetos de 2001. A fiscalização do conteúdo local é exercida por um órgão da própria PDVSA,

\footnotetext{
7 O PIB, que vinha crescendo a pouco mais de $3 \%$ ao ano, no período inicial do governo Chávez, caiu 8,8\% em 2002 e 7,7\% em 2003. O desemprego passou de $13 \%$ da população economicamente ativa para entre $16 \%$ e $17 \%$ no período da crise de 2002-2003; o aumento da formalização que chegara a 50\% em 2001 voltou ao nível de 47\% como aponta Barros (2006).
}

a Bariven, responsável por todas as contratações e que detém um cadastro de empresas de capital nacional, que devem ser objeto de prestação de serviços para atendimento dos requerimentos da PDVSA.

A participação governamental pela produção do petróleo, segundo Bain e Tozzini (2009), é de: a) royaltie, $30 \%$, (geral); $20 \%$ nos blocos localizados na Faja del Orinoco (para viabilizar economicamente a produção); b) royaltie adicional de $3,33 \%$; c) contribuição especial de $50 \%$ sobre a diferença entre o preço do barril e US\$ 70, até US\$ $100 / \mathrm{bbl}$, e $60 \%$ sobre a diferença entre o preço do barril e US\$ 100, a partir de US\$100; d) Imposto de Renda de 50\%; e) imposto de extração, de 33,33\% do valor do petróleo extraído; f) imposto de registro de exportação, de $0,1 \%$ sobre o petróleo exportado; g) imposto de superfície, de 100 unidades tributárias a cada quilômetro quadrados, mais $2 \%$ nos primeiros cinco anos e $5 \%$ nos anos seguintes; h) imposto de consumo próprio, de $10 \%$ do valor de cada $\mathrm{m} 3$ de derivados de hidrocarbonetos produzidos/consumidos como combustível em operações próprias; i) imposto sobre valor agregado, variável de $8 \%$ a $16,5 \%$; j) contribuição para desenvolvimento endógeno, de $1 \%$ do lucro antes de impostos da empresa mixta; $\mathrm{k}$ ) imposto-sombra, que complementa as arrecadações para alcançar o mínimo de $50 \%$ das receitas.

Nota-se que a forma institucional adotada pelo governo venezuelano difere da forma de cálculo da participação de outros países, especialmente porque, naquele país, os contratos firmados entre as companhias de exploração são necessariamente de formação de joint-venture com a companhia estatal PDVSA. O controle estatal fica evidente também pelo fato de que o instrumento contratual possui uma cláusula de venda dos hidrocarbonetos, que obriga a venda à PDVSA de todo o hidrocarboneto produzido e não utilizado na operação ou cedido sob a forma de royalties. Salienta-se ainda a presença do Impuesto Sombra, mais conhecido como a regra do fifty-fifty, que opera como um gatilho, para garantir que ao menos $50 \%$ da receita bruta das joint ventures fiquem em poder do Estado. Esse imposto só não é aplicável caso, após a aplicação dos demais tributos, o valor transferido ao Estado já ultrapasse a metade dos valores obtidos com a venda de hidrocarbonetos pela empresa mixta à PDVSA.

Em síntese, o governo venezuelano exerce o controle absoluto da produção de petróleo, por meio da participação acionária da PDVSA nas Empresas Mixtas. O instrumento contratual da 
empresa mixta determina um plano de produção e desenvolvimento, denominado Plano de Negócios. Além disso, apenas empresas estatais podem executar atividades de comercialização do petróleo bruto no âmbito nacional e internacional; o governo pode proibir por decreto a comercialização de derivados de petróleo e gás no âmbito nacional e internacional.

Do ponto de vista de arranjo institucional, a Arábia Saudita apresenta algumas peculiaridades por se tratar de uma monarquia com viés religioso. Para Bain e Tozzini (2009), o país árabe não possui um marco legal estabelecido, sequer existindo agências para a regulamentação do setor. Tais regras são ditadas em forma de Decretos Reais pelo Conselho Supremo do Petróleo, presidido pelo Rei Abdullah, que detém o controle de todas as ações da única empresa autorizada a explorar o petróleo no país, Saudi Arabian Oil Company (Saudi Aramco).

Sob esse aspecto, segundo Bain e Tozzini (2009), há o monopólio da Saudi Aramco nas atividades de exploração e produção de petróleo. Pode-se inferir, portanto, que as majors simplesmente não participam da exploração e produção de petróleo no país de maior produção mundial, o que se reflete também na inexistência de regulação das chamadas "participações governamentais", como os royalties, uma vez que a receita estatal se dá pelo lucro direto das vendas da produção. Nesse contexto, o interesse em analisar os aspectos institucionais da Arábia Saudita, quanto à exploração do petróleo, restringe-se à forma contratual diferenciada em relação aos outros quatro países estudados. Nesse aspecto, enfatiza-se apenas a existência de contratos de simples prestação de serviços.

De acordo com Bain e Tozzini (2009), no regime contratual de serviços, o pagamento aos prestadores é feito em espécie e os contratados não correm qualquer risco na exploração das jazidas, ou seja, o pagamento pelo serviço prestado independe, portanto, da descoberta de reservas. Existem, na realidade, duas modalidades contratuais no regime de serviços para contratação: (i) o contrato de serviço sem risco; (ii) o contrato de serviço com cláusula de risco. Todavia, na Arábia Saudita, a contratação dá-se, basicamente, na modalidade sem cláusula de risco.

Em síntese, do ponto de vista da participação direta do Estado na exploração de petróleo, fica evidente que a adaptações do contexto político de cada país, mas sempre voltadas para uma maior produção de petróleo. Nos Estados Unidos, o procedimento é de não atuação direta na explo- ração do petróleo e mantém-se certamente porque naquela economia essa é a maneira mais eficiente de exploração petrolífera. No Brasil, ainda que se adote o modelo americano de existência de agência reguladora, se entendeu que a existência de uma empresa com forte capital estatal seria a maneira mais eficiente de exploração, do mesmo modo que na Argentina e na Venezuela se entende de maneiras diversas para uma maior produção de petróleo, conforme se pode visualizar no quadro 1.

A análise do modo institucional pelo qual os países selecionados se utilizam para regular o mercado petrolífero em sua extração e produção, aponta para quatro realidades absolutamente distintas, onde na Argentina há a completa desregulação do setor, em que não existe agência reguladora e sequer uma empresa estatal atuando como player do mercado. Assim, ainda que existam leis aplicáveis pelo Poder Judiciário Argentino à exploração e produção do petróleo, não se trata de atuação estatal considerável do ponto de vista econômico.

Os Estados Unidos seguem a realidade argentina no que diz respeito à inexistência de empresa estatal atuando no mercado de extração e exploração. Por outro lado, possui ao menos 4 agências reguladoras com atuação considerável sobre o setor, com independência do governo, para regular o comportamento desse mercado.

A Venezuela apresenta um contexto institucional onde o Estado é detentor absoluto da exploração e produção do petróleo, através de uma companhia estatal que está presente em todas essas operações no território nacional, inexistindo, por isso, agência reguladora do setor, ainda que exista um órgão dependente da PDVSA para fiscalizar a produção e contratação de empresas prestadoras de serviços nacionais.

Já o Brasil, apresenta uma companhia estatal atuando como player do setor do petróleo, porém, em vista da abertura do setor, adotou a existência de agência reguladora, a exemplo dos Estados Unidos, porém com maior concentração de atribuições e com menor independência do governo.

\section{CONCLUSÕES}

Para a indústria de exploração de petróleo conclui-se que, nos países estudados, como Estados Unidos, Brasil, Argentina e Venezuela, a regulação econômica dá-se por intermédio de um processo político de decisão, confirmando a teoria proposta por Stigler (1971). Assim, para evitar a captura do Estado pelas empresas produtoras, os países 
Quadro 1. Demonstrativo-síntese da atual existência de agências reguladoras do setor e empresas estatais de exploração de acordo com o regime jurídico de exploração.

\begin{tabular}{|cccc|}
\hline País & $\begin{array}{c}\text { Número de agências } \\
\text { reguladoras }\end{array}$ & $\begin{array}{c}\text { Empresa estatal } \\
\text { produtora }\end{array}$ & $\begin{array}{c}\text { Regime institucional } \\
\text { de produção }\end{array}$ \\
\hline Argentina & - & - & concessão \\
\hline Estados Unidos & 4 & - & concessão \\
\hline Brasil & 1 & 1 & concessão \\
\hline Venezuela & - & 1 & joint-venture \\
\hline Arábia Saudita & - & 1 & Prestação de serviço \\
\hline
\end{tabular}

Fonte: Brito (2004), Campos (2004), Barros (2006), Matos et al (2005).

adotam um arranjo institucional que possibilita uma maior eficiência econômica, e adotam uma posição ao lado dos grupos de interesse que tendem a lucrar com o processo de transferência de renda, confirmando, nesse sentido, também as teorias de Peltzman (1976) e de Becker (1983). Essa tomada de posição política favorável à produção de petróleo fica evidente pela instituição de participações governamentais sobre a produção, conforme discutido por Laffont e Tirole $(1991,1993)$. Essa situação fica evidente no caso da Arábia Saudita, onde o governo passa inclusive a ser o único detentor da possibilidade de exploração e também o único a lucrar com a atividade.

Os resultados mostram que nos Estados Unidos e no Brasil, a produção é insuficiente para suprir a demanda de consumo interno. Em 2009, a produção norte-americana de petróleo supriu apenas $40,68 \%$ da capacidade de suas refinarias e $38,51 \%$ do consumo interno e, ainda que tenham capacidade muito acima da produção local, as refinarias conseguiram suprir apenas $94,66 \%$ da demanda do mercado interno. A economia brasileira, embora não seja grande consumidora mundial, apresenta um consumo de petróleo considerável para os padrões da América do Sul; porém, sua produção não é suficiente para suprir essa demanda, e ainda que se aumente a produção local, a capacidade de refino brasileira não atende ao aumento produtivo. Em 2009, a produção brasileira foi equivalente a $98,21 \%$ da capacidade das suas refinarias.

Diferentemente, a economia da Argentina consumiu, em 2009 , em torno de $74 \%$ da capacidade de refino, que representou $70 \%$ da produção interna de petróleo. Os resultados mostram também que a Venezuela tem a capacidade de refino bem superior ao consumo doméstico, podendo, portanto, exportar petróleo bruto e seus derivados. Já, no caso do maior produtor de petróleo mundial, a Arábia Saudita, as instalações de refino internas somente conseguem atender a $53,8 \%$ da produção.

Para a indústria de exploração de petróleo, nos Estados Unidos, Brasil, Argentina e Venezuela, a regulação econômica dá-se por intermédio de um processo de decisão e escolha política. Assim, para evitar a captura do Estado pelas empresas produtoras, os países adotam um arranjo institucional que possibilita uma maior eficiência econômica e adotam uma posição ao lado dos grupos de interesse que tendem a obter ganhos com o processo de transferência de renda. Mais especificamente, conclui-se que: (a) contratos de concessão de exploração são observados nos Estados Unidos, no Brasil e na Argentina; (b) contrato de joint-venture para a exploração é estabelecido na Venezuela; ou simplesmente (c) contratos de serviços são estabelecidos para o caso do governo saudita necessitar de alguma intervenção específica, em que não possua adequada tecnologia. Salienta-se ainda que os contratos de concessão de exploração de petróleo tendem a ser mais flexíveis nos Estados Unidos, no Brasil e na Argentina, permitindo que a tal atividade possa ser desenvolvida pela iniciativa privada, enquanto na Venezuela e na Arábia Saudita, uma empresa puramente estatal detém o monopólio no segmento petrolífero.

A título de sugestão para prosseguimento da pesquisa refere-se a matrizes energéticas dos países selecionados, de maneira a verificar-se se uma eventual mudança de modelo institucional teria impacto significativo na economia. Outra linha de investigação poderia ser direcionada aos efeitos dos esforços realizados pelos países no desenvolvimento de novas tecnologias, para a utilização de energia limpa e renovável. Para o 
caso brasileiro, sugere-se uma análise da questão das distribuições sociais da produção de petróleo, especialmente, com o aumento da produção, resultado das explorações da camada pré-sal.

\section{REFERÊNCIAS}

BAIN, C; TOZZINI, Freire. Regimes jurídico-regulatórios e contratuais de E\&P de petróleo e gás natural. Bain \& Company e Tozzini Freire Advogados, Relatório I 2009. Disponível em: <http://www.bndes.gov. br.>. Acesso em: 30 out. 2010.

BECKER, Gary. A theory of competition among pressure groups for political influence. Quarterly Journal of Economics, Cambridge, Mass., v. 98, n. 3, p. 371-400, Aug. 1983.

BRASIL. Lei 9.478, de 6 de agosto de 1997. Dispõe sobre a política energética nacional, as atividades relativas ao monopólio do petróleo, institui o Conselho Nacional de Política Energética e a Agência Nacional do Petróleo e dá outras providências. Diário Oficial [da República Federativa do Brasil], Brasília, DF. Disponível em: <http://www.planalto. gov.br.>. Acesso em: 30 out. 2010.

BRITO, Alírio Maciel Lima de; ANDRADE, Ronald Castro de. Regulação, livre concorrência e defesa do consumidor na indústria do petróleo: o papel da ANP. In: Congresso Brasileiro de P\&D em Petróleo \& Gás, 2.,2004 Rio de Janerio. Anais, Rio de Janerio 2004, $30 \mathrm{p}$.

CAMPOS, Adriana F. O processo de abertura do setor petrolífero na América Latina: os casos da Argentina, Bolívia e Chile. In: Congresso Brasileiro de P\&D em Petróleo \& Gás, 2.,2004 Cidade. Anais, cidade, 2004, $23 \mathrm{p}$.

CAMPOS, Adriana F. Transformações recentes no setor petrolífero brasileiro. Perspectiva Econômica on line, Unisinos, São Leopoldo, v. 1, n. 1, p. 68-81, jan./jun. 2005.

FIANI, Ronaldo. Afinal, a quais interesses serve a regulação? Economia e Sociedade, Campinas, v. 13, n. 2 , p. $81-105$, jul./dez. 2004.

GALA, Paulo. A teoria institucional de Duglass North. Revista de Economia Política, v. 23, n. 2, p. 89-105, abr./jun. 2003.
KRUGMAN, Paul R.; OBSTFELD Maurice. Economia internacional: teoria e política. São Paulo: Pearson Addison Wesley, 2007.

LAFFONT, Jean-Jacques; TIROLE, Jean. A theory of incentives in procurement and regulation. Cambridge, Mass.: The MIT Press, 1993.

MARQUES-PEREIRA, J. Trabalho, cidadania e eficiência da regulação econômica. In: THÉRET, B.; BRAGA, J. C. S. (Org.). Regulação econômica e globalização. Campinas: Instituto de Economia da Unicamp, 1998. p. 321-350.

MATOS, Fernanda Laís; COSTA, Isabel Soares; XAVIER, Yanko Marcius de Alencar. Regulação e agências reguladoras nos Estados Unidos da América e suas influências para a indústria do petróleo no Brasil. In: Congresso Brasileiro de P \& D em Petróleo \& Gás, 3, 2005, Salvador, BA. Anais..., Salvador, out/2005

MELLO, Eduardo Santos do Amaral. Os desafios da ANP na defesa dos interesses dos consumidores: a proposta de um centro de relações com os consumidores. In: SUSLICK, Saul B. (Coord.). Regulação em petróleo e gás natural. Campinas: Komedi, 2001.

NUNES, Edson; RIBEIRO, Leandro; PEIXOTO, Vitor. Agências reguladoras no Brasil. Observatório Universitário on line. 2007, 25 p. (Documento de trabalho n. 65).

OPEP. Annual Statistic Boulletin - 2009, OPEP, 2010.

PELTZMAN, Sam; LEVINE, E. Michael; NOLL, Roger G. The economic theory of regulation after a decade of deregulation. Brooking Papers on Economic Activity. Microeconomics. The Brooking Institution, v. 1989, p. 1-59, 1989.

PIRES, Adriano; CAMPOS FILHO, Leonardo. A abertura do setor petróleo e gás natural: retrospectiva e desafios futuros. In: GIAMBIAGI, Fabio; REIS, José Guilherme; URANI, André (Org.). Reformas no Brasil: balanço e agenda. Rio de Janeiro: Nova Fronteira, 2004.

QUEIROZ, Carlos R. A.; POSTALI, Fernando A. S. Royalties e arrecadação municipal: apontando ineficiências do sistema de divisão das rendas do petróleo no Brasil. Temas de economia aplicada: informações Fipe, São Paulo, p. 12-16, ago. 2010. 
SERRA, R. V. Desdobramento espacial da exploração e produção de petróleo no Brasil: em busca de um nexo para a exploração de petróleo entre os municípios. In: Encontro Nacional da ANPUR, 10, 2003, Belo Horizonte. Anais... Belo Horizonte, 2003.

SIBLEY, David, Price cap: regulation incentive and asymmetric information. Rand Journal of Economics, n. 20, v. 3, p. 25-30, Autumn 1989.

STATISTICAL REVIEW of world energy. British Petroleum, 2010.

STIGLER, George J. The theory of economic regulation. Bell Journal of Economics and Management Science, New York, v. 2, n. 1, p. 1-20, Spring 1971.

SUSLICK, Saul B. A dinâmica na regulação de petróleo e gás natural. In: SUSLICK, Saul B. (Coord.). Regulação em petróleo e gás natural. Campinas: Komedi, 2001.

TRICHES, Divanildo. Regulamentação da concessão dos serviços de utilidade pública: da teoria a prática. In: Encontro de Economia e Econometria da Região Sul, I, 1998, Florianópolis, SC. Anais... Florianópolis CDROM, 1998, v. 1, 17 p, set/1998.

VALOIS, Paulo. A evolução do monopólio estatal do petróleo. Rio de Janeiro: Lumen Juris, 2000.

WORLD development indicators database. World Bank, 2010. 